\title{
Outcome of Rehabilitation of Articular Cartilage Knee Defect after Autologous Osteochondral Transplantation
}

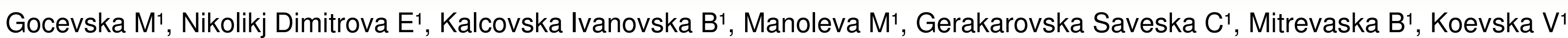

${ }^{1}$ Institute for Physical Medicine and Rehabilitation, Medical Faculty, "Ss Ciryl and Methodius" University, Skopje, R. Macedonia

\section{INTRODUCTION}

The osteochondral transplantation (OCT) is a well accepted treatment option for focal cartilage lesions in the knee joint. Repair of full thickness defects of articular cartilage in the knee is difficult but important to prevent osteoarthritis.

\section{PURPOSE}

The purpose of this study is to report outcome measures after rehabilitation of autologous osteochondral transplantation in a patient with articular cartilage in the left knee .

\section{MATERIAL AND METHOD}

The patient A.G, 23 years old at follow-up. Six weeks after osteochondral allograft the patient was referred for outpatient rehabilitation.

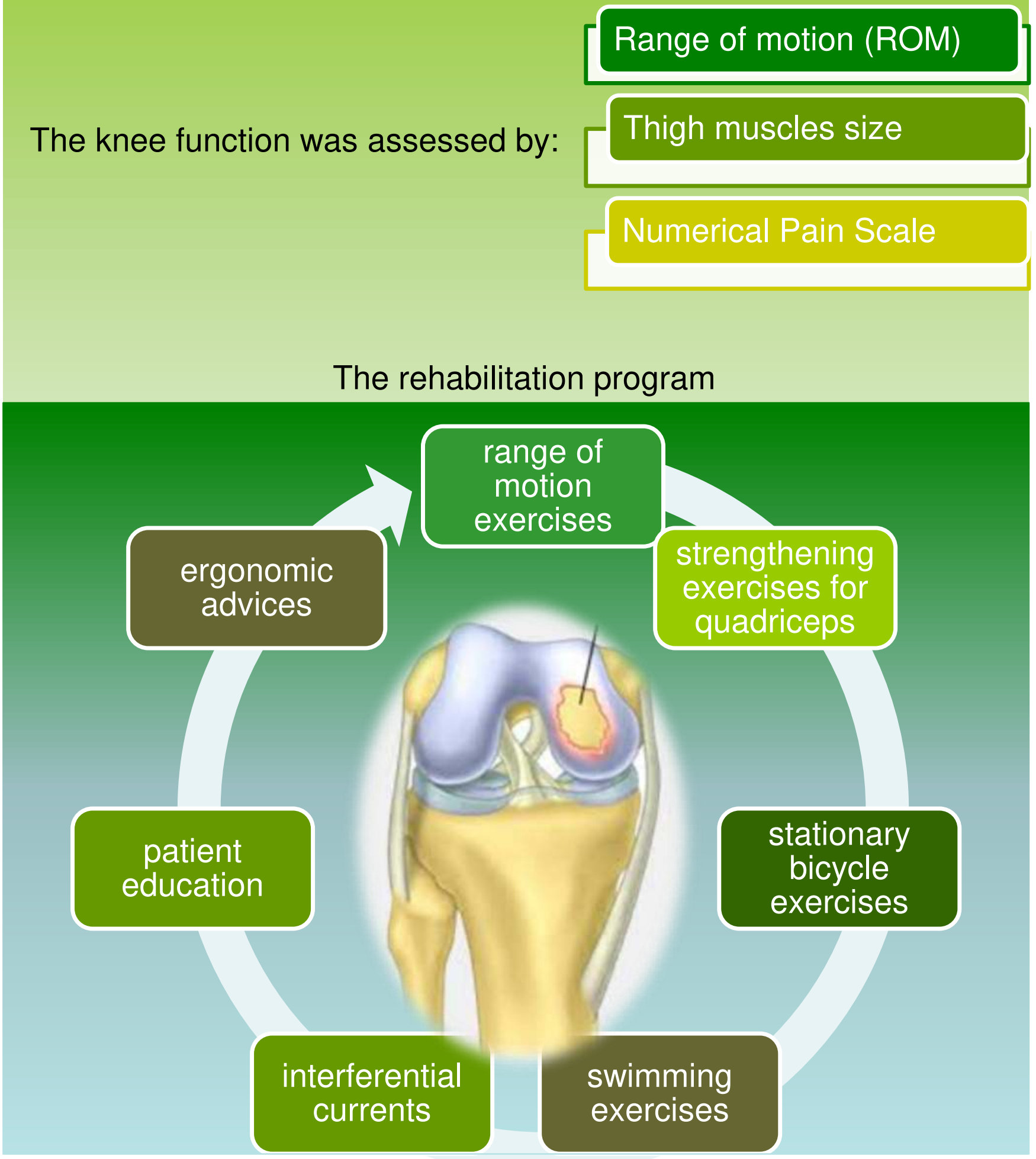

\section{RESULTS}

\begin{tabular}{|c|c|c|}
\hline KNEE RANGE OF MOTION & Flexion & Extension \\
\hline Baseline & $105^{\circ}$ & $-5^{0}$ \\
\hline After two weeks & $130^{\circ}$ & $0^{0}$ \\
\hline
\end{tabular}

THIGH MUSCLES SIZE (cm)

Baseline

$44 \mathrm{~cm}$

After two weeks

$42 \mathrm{~cm}$

\section{PAIN SCORE 0 - 10 NUMERICAL RATING SCALE}

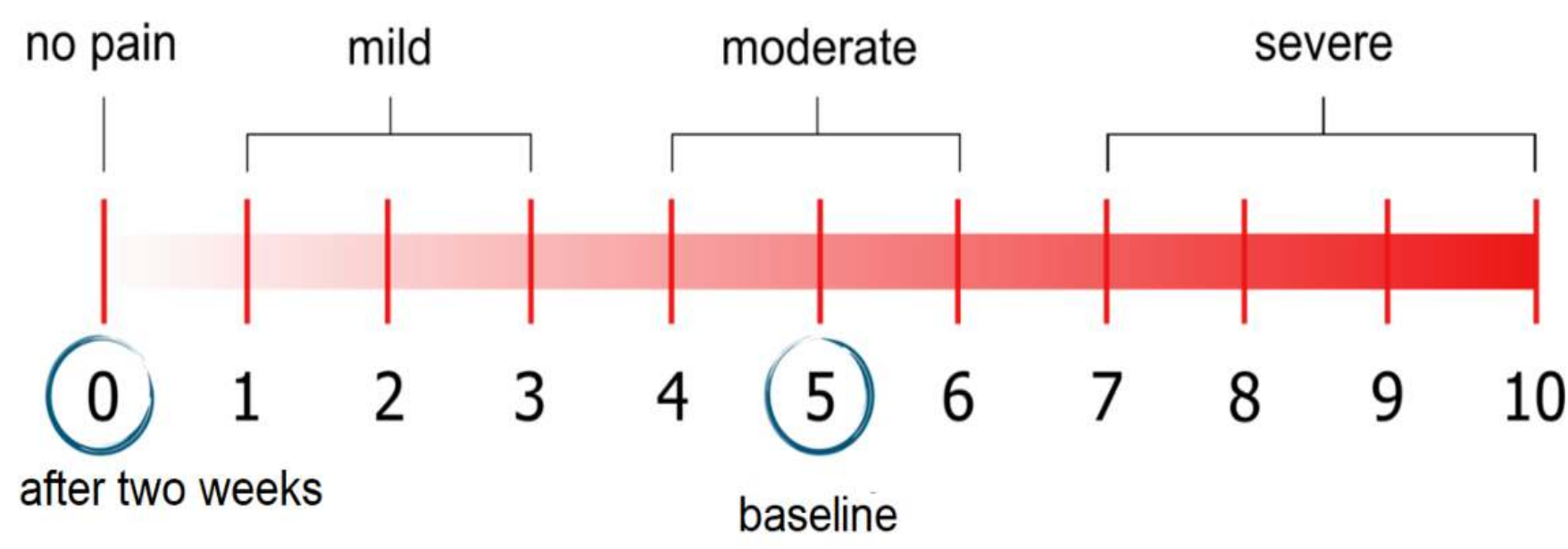

\section{DISCUSSION}

The articular cartilage is a layer of hyaline cartilage that covers the end of bones that articulate with other bones. Articular cartilage is critical for people joint function. It is vulnerable to traumatic injury and has no capacity to regenerate.(1) Patient with significant chondral defencts frequently have persistent joint line pain, swelling and catching in the knee.(2) Osteochondral transplantation is currently the only procedure that restores the normal hyaline articular cartilage to the injured knee.(3) Post-operative rehabilitation will focus on regaining range of motion and protect the healing plugs. As the rehabilitation progresses the focus shifts to regaining strengt and movement control.

\section{CONCLUSION}

Cartilage knee defects are often associated with continued patient symptoms and can lead to progressive onset of early osteoarthritis, although the exact incidence is unknown. Implementation of a regular rehabilitation treatment after osteochondral transplantatioin in the knee, has essential importance and is strongly recommended.

\section{REFERENCES:}

